\title{
High-Density DArT Markers and Phenotypic Characterization of Cowpea Accessions (Vigna unguiculata (L.) Walp)
}

\author{
B. G. Adu $\mathbb{D}^{1},{ }^{1}$ R. Adu Amoah $\mathbb{D}^{1},{ }^{1}$ L. M. Aboagye, ${ }^{1}$ M. G. Abdoul Aziz, ${ }^{2}$ and R. Boampong $\mathbb{D}^{1}$ \\ ${ }^{1}$ Council for Scientific and Industrial Research - Plant Genetic Resources Research Institute, Bunso, Ghana \\ ${ }^{2}$ Department of Civil Engineering, Kwame Nkrumah University of Science and Technology, Kumasi, Ghana \\ Correspondence should be addressed to B. G. Adu; bg.adu@csir.org.gh
}

Received 25 April 2021; Accepted 12 October 2021; Published 25 October 2021

Academic Editor: Othmane Merah

Copyright (c) 2021 B. G. Adu et al. This is an open access article distributed under the Creative Commons Attribution License, which permits unrestricted use, distribution, and reproduction in any medium, provided the original work is properly cited.

Cowpea (Vigna unguiculata (L.) Walp) is an important component of most traditional cropping systems in the tropics. It provides leafy vegetables and/or grains and forages and acts as a cover crop. We characterized 16 cowpea accession collections in Ghana using agromorphological traits and high-density silicoDArT markers for breeding and efficient conservational purposes. Principal component analysis indicated pod, leaf, and seed characters such as pod length, seeds per pod, terminal leaves shape, number of leaves, hundred seed weight, and seed weight per plant as discriminatory traits in revealing the variation among the accessions. Trait association analysis revealed a significant correlation between the pod number, pod length, seeds per pod, number of leaves, and seed weight per plant that could allow the selection to improve the grain yield. Moderate to high broad-sense heritability and genetic advance observed for most of the traits indicate that the selection would result in foreseeable genetic improvement. The 9,706 silicoDArT markers used in the study were able to reveal genetic variation among the tested cowpea collections. Accessions GH5039 and GH6056 were established as duplicates based on the silicoDArT markers, which could enhance efficient germplasm utilization and conservation. Accessions GH3685, GH3674, and GH4541 were identified for high leaf and pod production and high seed yield per plant, which could be good candidates for dual purpose cowpea production, which is common in the subsistence farming system.

\section{Introduction}

Cowpea is an economically important indigenous African legume crop and a major source of plant proteins, vitamins $[1,2]$, animal fodder [3], and is of considerable importance in human nutrition in the semiarid and tropical regions of Africa [4]. Cowpea is also well adapted to the semiarid regions of the tropics where other food legumes do not perform well due to its ability to tolerate drought and high temperature. It performs well even in poor soils and has the unique ability to fix atmospheric nitrogen [5]. The young leaves, green pods, and green seeds are used as vegetables, whereas dry seeds are used in a variety of food preparations [6]. Collectively, these characteristics have made cowpea an important component of subsistence agriculture, particularly in the dry savannas of sub-Saharan Africa, which has brought about the importance of developing "dual purpose" cowpea varieties with the ability to produce high seed and leaf yield [7].
In Ghana, Plant Genetic Resource and Research Institute of Ghana (PGRRI), a subsidiary of Council for Scientific and Industrial Research (CSIR) with several collections of cowpea accessions in conservation has the mandate to collect, characterize, evaluate, document, conserve, distribute, and utilize plant genetic resources. These activities are fundamental, following continues threat of plant genetic resources through human activities and natural disasters [8]. Knowledge about the diversity or variation in a given germplasm forms the basis for breeding, efficient management, and conservation. Prebreeding activities, such as characterization and evaluation, enhance genetic resource conservation and promote the identification of favorable alleles of genes related to important agronomic traits in the germplasm for subsequent incorporation into crop improvement programmes [9].

The characterization of germplasm can be achieved through morphological and molecular markers. Observed 
variations based on agromorphological descriptors are important; however, the use of morphological traits has been ineffective for the complete understanding of the genetic variability in germplasm collections due to the phenotypic plasticity of genotypes [10, 11]. Hence, agromorphological descriptors should be complemented with molecular markers for efficient and reliable genetic diversity studies and germplasm management $[12,13]$.

Several DNA marker systems such as diversity array technology (DArT), restriction fragment length polymorphisms (RFLPs), random amplified polymorphic DNAs (RAPDs), amplified fragment length polymorphisms (AFLPs), single nucleotide polymorphisms (SNPs), and simple sequence repeats (SSRs) are available for genetic study in cowpea and other crop species [14-16]. They offer numerous advantages over phenotype- 0 alternatives as they are stable and detectable in all tissues of the plant at any growth stage. Diversity array technology (DArT) is a sequence and electrophoresis independent technique that can generate hundreds of molecular markers that cover the entire genome in a single and reliable assay [17]. DArT was first established in rice [17], and the technique has been applied to a range of other crops and fish species [18-20]. It has been recently used in combination with phenotypic characters to identify putative QTLs associated with drought stress-response traits in soybean hybrid populations [15]. Similarly, [19] used DArT in genetic dissection of yield associated traits in a cross between cowpea and yard-long bean.

Some work has been carried out on cowpea accessions $[21,22]$; however, high-density DNA markers that cover the entire genome are yet to be applied to them. Therefore, this work was done with the objective to assess genetic diversity among some cowpea accessions using morphological and diversity array technology markers (silicoDArT).

Specifically, this study sought to

(a) Characterize 16 cowpea germplasm using qualitative and quantitative traits based on the cowpea descriptor

(b) Estimate the correlation among traits, heritability, and genetic advance expected

(c) Assess genetic diversity among the accessions at the molecular level using high-density DArT markers

\section{Materials and Methods}

2.1. Location and Experimental Materials. The study was carried out at the research field of the CSIR-Plant Genetic Resources Research Institute at Bunso in the Abuakwa South Municipal of the Eastern Region of Ghana between April and November of 2020. Bunso (lat. $06^{\circ} 46^{\prime} \mathrm{N}$, long. $0101^{\prime} \mathrm{W}$, $149 \mathrm{~m}$ above sea level) lies in the semideciduous forest zone of Ghana with the soil type Nta series (FAO: Gleyic Arensol) [23].

Sixteen cowpea accessions were used in the study (Table 1). These were local cowpea landraces collected from various regions of Ghana and conserved at the CSIR-Plant Genetic Resource Research Institute.
2.2. Experimental Design. Seed multiplication became necessary between April and June for fresh healthy viable seeds for uniform replication of the accessions in the main experiment between September and November, 2020. The main experiment was laid in a randomized complete block design with three replications. Each accession was planted in a plot with two rows of $5 \mathrm{~m}$ long at a spacing of $0.5 \mathrm{~m}$ between and within rows giving a plot size of $2.5 \mathrm{~m}^{2}$, while the space between plots was $1 \mathrm{~m}$. Agronomic practices for cowpea production were followed with neither fertilization nor irrigation. Climbing lines were staked prior to flowering.

2.3. Morphological Characterization. Data were collected from thirty-one agromorphological characters (qualitative and quantitative) following the International Board for Plant Genetic Resources (IBPGR) [24] descriptors for cowpea (Table 2). Seed weight per plant (SWTP) and hundred seed weight (HSW) were determined at $14 \%$ seed moisture content.

2.4. Molecular Characterization. Cowpea seedlings were allowed to grow to the three-leaf stage before fresh leaves were harvested for DNA extraction using the DArT DNA extraction protocol [25] at the Agricultural Biotechnology Laboratory, Faculty of Agriculture, Kwame Nkrumah University of Science and Technology, Ghana. DNA concentrations were diluted between 50 and $100 \mathrm{ng} / \mu \mathrm{l}$ following analysis using a NanoDrop 2000c spectrophotometer (NanoDrop Lite, LT2878, Thermo Scientific, USA) before shipping to Diversity Array Technology Incorporation, Australia for genotyping.

Genotyping was performed using a combination of DArT complexity reduction methods as outlined by Kilian [25]. The complexity reduction method used involved digestion with the methylation-sensitive restriction enzyme PstI and frequently cutting enzymes AluI, BstNI, TaqI, or MseI [26]. Markers were scored "1" for presence, "0" for absence, and "-" for calls with nonzero count but too low counts to score confidently as "1". A total of 18075 silicoDArT markers were developed for the accessions under order DCpe18-3507. The reads were aligned to the model reference cowpea v2016_003. Marker quality parameters, such as percentage call rate, reproducibility, and polymorphic information content (PIC) values, were used to trim the markers. The most informative silicoDArT markers were selected based on a threshold PIC value $\geq 0.1$ and $100 \%$ reproducibility. The call rate percentage was also used to eliminate markers with $\geq 10 \%$ missing data.

2.5. Estimation of Variance Components and Data Analysis. Genotypic and phenotypic variance, heritability (broadsense), and genetic advance of selected agronomic traits were estimated following the methods described below:

$$
\text { environmental variance } \boldsymbol{\sigma}^{2} \mathbf{e}=\text { MSE, }
$$

where MSE = error mean square, 
TABLE 1: Some passport data on cowpea accessions used for the study.

\begin{tabular}{|c|c|c|c|c|}
\hline Accessions & Local name & Region of Ghana & Specific location & Seed coat \\
\hline GH3674 & Eveyi & Volta & Bame Anyirawase & Mottled black \\
\hline GH5039 & Akye & Eastern & Abonse & Red \\
\hline GH6045 & Soronko & Ashanti & Fumesua & Brown \\
\hline GH7221 & Sompla & Upper west & Kong & Mottled black \\
\hline GH3701 & Sanji & Northern & Kpong & Mottled brown \\
\hline GH6056 & Asedua & Eastern & Abonse & Red \\
\hline GH3707 & Benga & Upper west & Tanina & Mottled brown \\
\hline GH7230 & Bene & Upper west & Kalsegra & Mottled brown \\
\hline GH3685 & Asedua & Brong ahafo & Fakuokrom & Red \\
\hline GH7245 & Sonorni & Upper west & Kunchugu & Mottled brown \\
\hline GH4541 & Ayi & Volta & Ziope & Mottled brown \\
\hline GH3710 & Tua & Northern & Nabori & Mottled black \\
\hline GH7218 & Sona & Upper east & Babison & Cream \\
\hline GH7235 & Bene & Upper west & Kalsegra & Mottled black \\
\hline GH3678 & Yor & Eastern & Aberewanko & Mottled black \\
\hline GH3907 & None & Northern & Nabori & Mottled brown \\
\hline
\end{tabular}

TABLE 2: Traits of cowpea assessed during the study based on the IBPGR cowpea descriptor.

\begin{tabular}{lc}
\hline Quantitative & Qualitative \\
\hline Days to 50\% flowering (X50.Flo) & Leaf colour (LVCOL) \\
Days to 50\% maturity (X50.MAT) & Plant pigmentation (PPIG) \\
Leaf length (LVLNG) & Flower colour \\
Leaf width (LVWID) & Pod attachment to peduncle \\
Leaves per plant (LVNESS) & Raceme position (RPOS) \\
Plant height (PH) & Seed colour (SDCOL) \\
Pod number per plant (PNP) & Seed shape (SDSH) \\
Pod length (PDL) & Terminal leaf shape (TLSH) \\
Hundred pod weight (HPDWT) & Growth habit (GH) \\
Peduncle length (PedL) & Twining tendency (TTEN) \\
Pods per peduncle (PDPP) & Pod curvature (PDCUR) \\
Seeds per pod (SPPD) & Immature pod pigmentation \\
Seed weight per plant (SWTP) & (IPP) \\
Hundred seed weight (HSWT) & Seed eye colour (ECOL) \\
Seed length (SDLNG) & Growth pattern \\
Seed width (SDWID) &
\end{tabular}

$$
\text { genotypic variance, } \boldsymbol{\sigma}^{2} \mathbf{g}=\frac{M S G-M S E}{r},
$$

where $\sigma^{2} g=$ genotypic variance, $\mathrm{MSG}=$ genotype mean square, and $r=$ number of replications.

Phenotypic variance $\sigma^{2} p=\sigma^{2} g+\sigma^{2} e$, where $\sigma^{2} g=$ genotypic variance.

Broad-sense heritability: the heritability in broad sense was estimated as

$$
H_{b}^{2}=\frac{\sigma^{2} g}{\sigma^{2} p} \times 100
$$

where $H_{b}^{2}=$ broad-sense heritability, $\sigma^{2} g$ = genotypic variance, and $\sigma^{2} p=$ phenotypic variance.

Genetic advance: genetic advance was calculated as $\mathrm{GA}=K . \sigma_{P} \cdot \mathrm{H}_{b}^{2}(3)$, where $\sigma_{P}=$ phenotypic standard deviation, $\mathrm{H}_{b}^{2}=$ broad-sense heritability, and $K=$ selection intensity $(\mathrm{K}$ at $5 \%=2.06)$.
Phenotypic correlation coefficients were calculated according to a procedure suggested in [28] using the variance and covariance components elaborated as follows:

$$
P(x y)=\frac{P_{\text {cov }} x \cdot y}{\sqrt{\sigma^{2}} p x \cdot \sigma^{2} p y},
$$

where $P(x y)=$ phenotypic correlation coefficient between the characters $x$ and $y, p_{\mathrm{cov}} x \cdot y=$ covariance between $x$ and $y$, $\sigma_{\mathrm{px}}^{2}=$ variance of $x$, and $\sigma_{\mathrm{py}}^{2}=$ variance of $y$.

The R statistical programme was used for the analysis of variance (ANOVA), and means were separated at 5\% LSD [29]. The principal component analysis of the morphological traits was performed using "FactoMiner" and "Factoextra" $\mathrm{R}$ packages [30]. Gower's dissimilarity indices and average linkage dendrogram for both morphological and silicoDArT data were computed using "cluster" and "pvclust" package in $\mathrm{R}[31,32]$. The "Hmisc" and "PerformanceAnalytics" package were used for the Pearson phenotypic correlation matrix and plot among traits [33]. The correlation between both marker systems was determined using the Mantel test, and the "ggplot2" package was used to generate the Mantel test scatterplot [34].

\section{Results}

3.1. Qualitative Traits Variability in the Accessions. There were variations in the various qualitative traits that were scored for the accessions (Supplementary 1) with exception of flower colour and growth pattern, which were violet and indeterminate throughout. Most of the accessions had a vigorous growth due to the production of new healthy seeds during the multiplication process. The genotypes exhibited diverse growth habits. With the exception of GH5039 and GH6056, which were semierect, the rest had prostrate to climbing growth habit. Based on the terminal leaf shape, genotypes were assorted into hastate (GH5039 and GH6056), subhastate (GH3710), and the rest had subglobose terminal leaf shape. The colour of the terminal leaves ranged from pale green to dark green. The latter was 
predominant $(>50 \%)$. All the three variants of the pod attachment to peduncle were present; however, the pendant type was dominant (62\%). Only accession GH3710 had extensively and uniformly pigmented plants and pods, while others had moderate to intermediate pigmented plants and pods.

Dry pod colour varied among the accessions. The accessions had different shades of brown as the colour of the dry pod except GH3685 and Gh3710, which were dark brown to black. Regarding the seed coat colour, some accessions had entirely one colour (38\%), while others had a mottled (marked with spots of colours) seed coat.

3.2. Quantitative Traits of the Accessions. There was significant $(P<0.05)$ genotype difference for the measured traits except for the average seed length (Table 3). Days for $50 \%$ flowering (X50.FLO) of the test genotypes ranged from 38 to 42 (GH6045) with a mean of 40 days. The average days to maturity (X50.MAT) was 55 days with accession GH7230 being relatively early maturing at 52 days. For the growth parameters, accessions GH5039 and GH6056 with hastate leaf shape had the longest leaf length $(>13 \mathrm{~cm})$ but short leaf width $(<6 \mathrm{~cm})$. Yield in terms of the average number of leaves per plant ranged between 103 (GH3685), 98 (GH6045), 95 (GH3674) to <70 for GH5039 and GH6056. The number of pods per plant (PNP) significantly varied among the accessions with a mean of 31.12 pods. Genotypes GH3710 and GH4541 had the highest number of pods per plant ( $>39$ pods), while GH3701 and GH7245 had the least ( $<25$ pods). The pod length ranged between $14.64 \mathrm{~cm}$ (GH7245) to $20.32 \mathrm{~cm}$ (GH3685) with a mean of $17.02 \mathrm{~cm}$. Again, GH3685 had the highest hundred pod weight (HPDWT) of $311.33 \mathrm{~g}$ after thorough drying. Accessions GH3675 and GH3685 recorded the highest number of seeds per pod (>17 seeds/pod). Similarly, GH4541 gave the highest $(70.30 \mathrm{~g})$ seed weight per plant (SWTP), followed by GH3685 and GH3674 (>63g), while GH7245 had the lowest $(<40 \mathrm{~g})$. GH6045, GH7221, GH3685, and GH7235 had the heaviest hundred seed weight ( $>14 \mathrm{~g} / 100$ seeds). GH6045 once more had the longest peduncle length (PedL) of $52.43 \mathrm{~cm}$ on which the pods were borne with a mean of 39.74 across accessions.

3.3. Trait Contribution to the Observed Variability. The first seven principal components with eigen values $>1$ explained $87.17 \%$ of the total variation exhibited by the agromorphological traits. The specific traits that made significant contribution to each principal component axis or dimension (dim) are shown in Figure 1. The first and second principal components (PCs) accounted for 30.9\% and $16.6 \%$ of the total variation, respectively. PC1 was highly associated with attributes of the pod, such as pod length (PDL), hundred pod weight (HPDWT), and seeds per pod (SPPD), while the leaf characters such as leaf length (LVLNG), leaf width (LVWID), terminal leaf shape (TLSH), and number of leaves (LVNESS) were correlated with PC2. Seed and pod characters such as seed shape (SDSH), number of pods (PNP), seed weight per plant
(SWTP), days to maturity (X50.MAT), and others were also highly correlated with PC7, which explained $4.3 \%$ of the total variation.

3.4. Relationship among Traits. Figure 2 presents a biplot indicating the genotypic relationship among traits and accessions. From the biplot, the dimension of the angle between traits determined whether traits have either positive or negative association. An acute angle observed between traits is responsible for positive association, while a large/obtuse angle is responsible for negative association. From the biplot, the angles of vectors between hundred pod weight (HPDWT), seeds per pod (SPPD), penducle length (PedL), and pod length (PDL), as well as SWTP, HSWT, SDWID, and SDLNG, were very acute. Same applies to the number of leaves (LVNESS), leaf width (LVWID), and plant height $(\mathrm{PH})$, indicating a positive association among them, and these were associated with the following accessions: GH4541, GH7235, GH6045, GH3685, GH7221, and GH3674. The contrast was observed between the pod length (PDL) and the number of pods per plant (PNP), growth habit $(\mathrm{GH})$, seed shape (SDSH), seeds per pod (SPPD), and pods per peduncle (PDPP), indicating strong negative association among them.

Phenotypic correlation coefficients among some traits summarized in Figure 3 corroborated what was revealed by the PCA biplot above. Pod length (PDL) had a strong significant $(P \leq 0.05)$ correlation coefficient with seeds per pod $(r=0.83)$, leaf width and days to $50 \%$ flowering $(r=0.64)$, and number of leaves and leaf width $(r=0.72)$. The relationships between the seed weight per plant (SWTP) and pod number per plant (PNP, $r=0.60$ ) and pod length (PDL) and seeds per pod (SPPD, $r=0.76)$ were positive. There were significant $(P \leq 0.05)$ positive correlations between the following traits: PDL with LVLNG $(r=0.62)$ and PedL $(r=0.71), \mathrm{GH}$ and TTEN $(r=0.90)$, X50.FLO with X50.MAT $(r=0.66)$, while negative correlations were observed between PNP and HSWT $(r=-0.62)$ and PDL with TTEN $(r=-0.88)$.

3.5. Variance Components and Heritability of Quantitative Traits. Variance components and heritability in broadsense $\left(h^{2} b\right)$ of characters with significant $(P<0.05)$ mean squares are presented in Table 4. Phenotypic variance $\left(\sigma^{2} \mathrm{p}\right)$ was higher than the genotypic variance across traits. Genotypic variance $\left(\sigma^{2} \mathrm{~g}\right)$ for most of the traits, except for the number of pods per plant (PNP), seed weight per plant (SWTP), and plant height, were higher than their respective error variance $\left(\sigma^{2}\right.$ e) leading to high broad-sense heritability $\left(h^{2} b\right)$ estimates $(>0.60)$. The heritability $\left(h^{2} b\right)$ estimate ranged between 0.29 and 0.94 for PNP and pod length, respectively. The seed weight per plant had a moderate heritability estimate of 0.39 , while that of the number of leaves per plant (LVNESS) was 0.63 . Genetic advance (GA) was computed to vary among the traits, indicating the varying gene action and environmental influence on the expression of the traits. The estimated genetic advance relative to the mean (GAM) of the various 


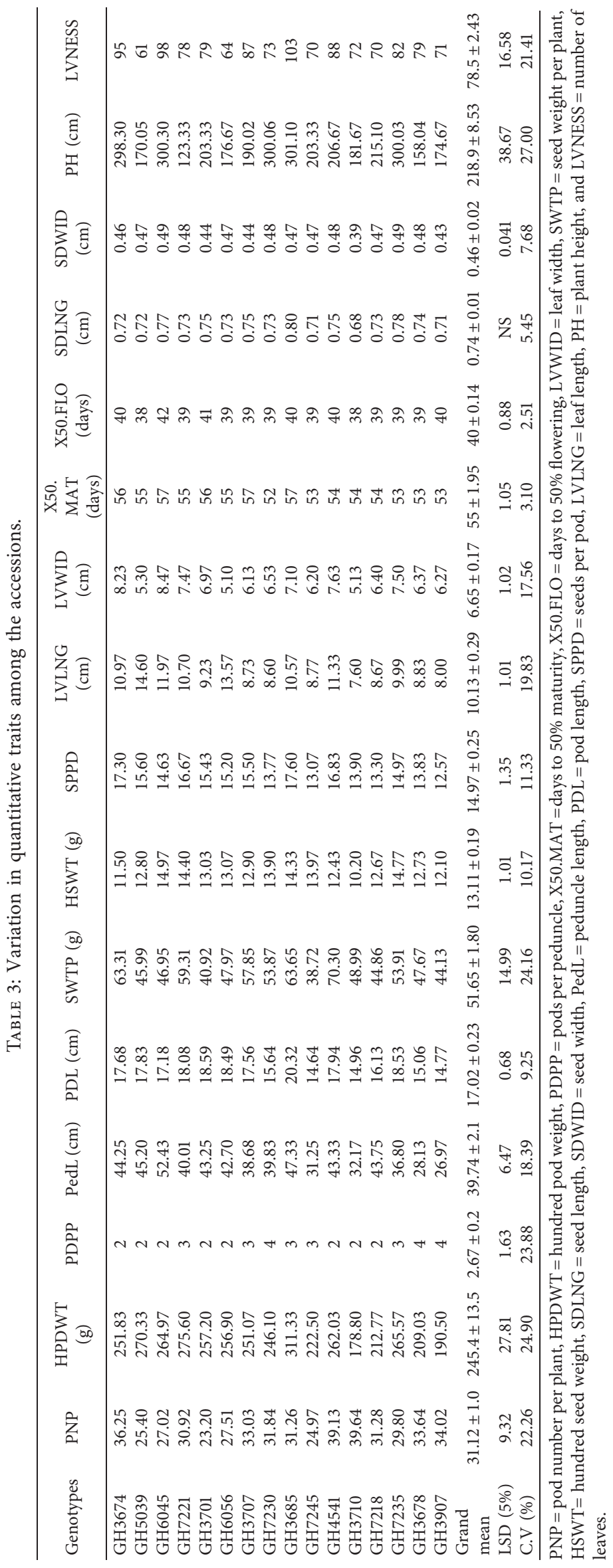



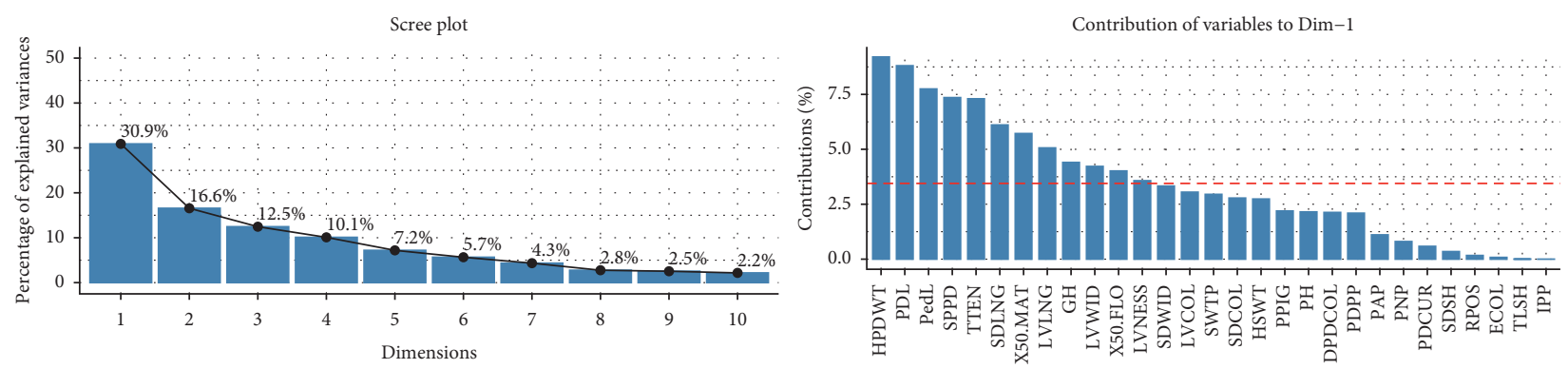

Contribution of variables to Dim-2
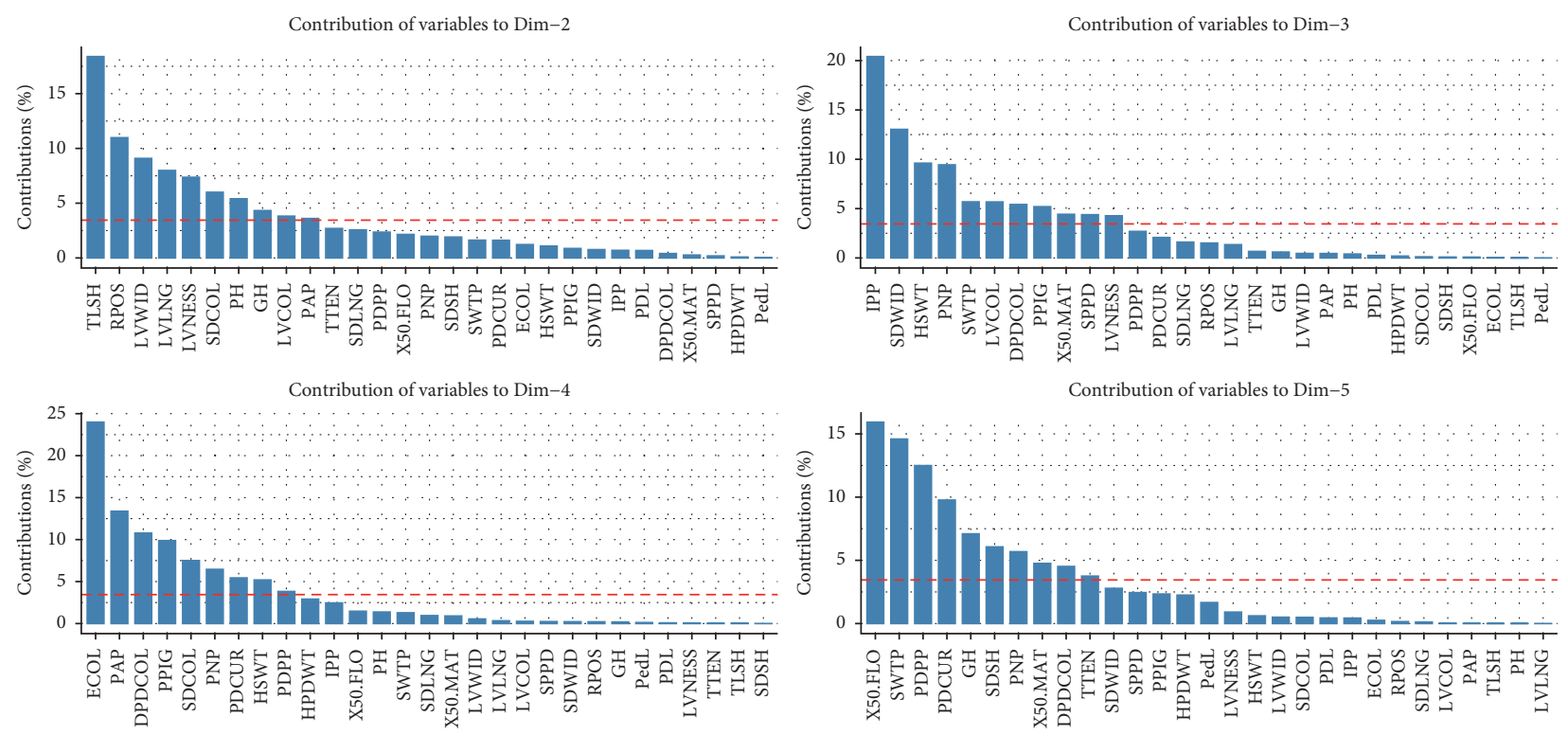

Figure 1: Principal component analysis of traits and contribution to each components.

traits for the population ranged between $3.74 \%$ for days to $50 \%$ flowering (X50\%FLO) to $37.32 \%$ for leaf length (LVLNG). The number of leaves per plant (LVNESS) and seed weight per plant had a GAM of $33.22 \%$ and $20.13 \%$, respectively.

3.6. Relationship among Accessions. The relationship among the accessions was determined at the molecular and morphological level. The agromorphological data were used to estimate Gower's dissimilarity indices among the accessions (Supplementary 2). With an average dissimilarity of 0.35 , the highest dissimilarity of 0.55 was recorded between GH6045 and GH3710, while the lowest (0.11) was between GH5039 and GH6056. The optimal cluster for grouping of the accessions was found to be two or three (Supplementary 3). Dendrogram based on dissimilarity matrix gave three clusters with six (GH3710, GH7218, GH7230, GH7245, GH3678, and GH3907), two (GH5039 and GH6056), and eight individuals in cluster one, two, and three, respectively (Figure 4(a)). Cluster one (C1) consisted principally of accessions, which were relatively early flowering and maturing with more pods per plant, while cluster three (C3) was made of accessions, which had numerous leaves with long pods and a high number of seeds per pod. Cluster two (C2) consisted of two accessions with long slender leaves.
Regarding the silicoDArT data, 18075 silicoDArT markers were developed for the cowpea accessions. Out of the 18075 silicoDArT markers, 9706 markers passed the quality test of $\geq 90 \%$ call rate, $100 \%$ reproducibility, and $\geq 10$ polymorphic information content (PIC) and were selected for further analysis (Supplementary 4). The average PIC of the selected markers was 0.34 with a range of $0.1-0.5$. The selected markers were used to estimate the genetic distance among the accessions based on Gower's dissimilarity index (Supplementary 5). Similar to the agromorphological traits, the lowest dissimilarity index of 0.01 was recorded between GH5039 and GH6056, which was within the threshold of replicated DNAs (duplicate), while the highest (0.52) was found between six different accessions.

The dendrogram developed based on the DArT markers using the average linkage method gave three main clusters with seven, one (GH3685), and eight accessions per cluster (Figure 4(b)). Accessions GH7245, GH3710, GH7218, and GH3678 clustered together, as well as GH7235 and GH7221. Similarly, GH6045, GH3674, GH4541, and GH3707 grouped together as it did with the phenotypic data.

Furthermore, the agromorphological and molecular silicoDArT dissimilarity matrices exhibited a moderate correlation $(r=0.13)$ when subjected to the Mantel test (Supplementary 6). 


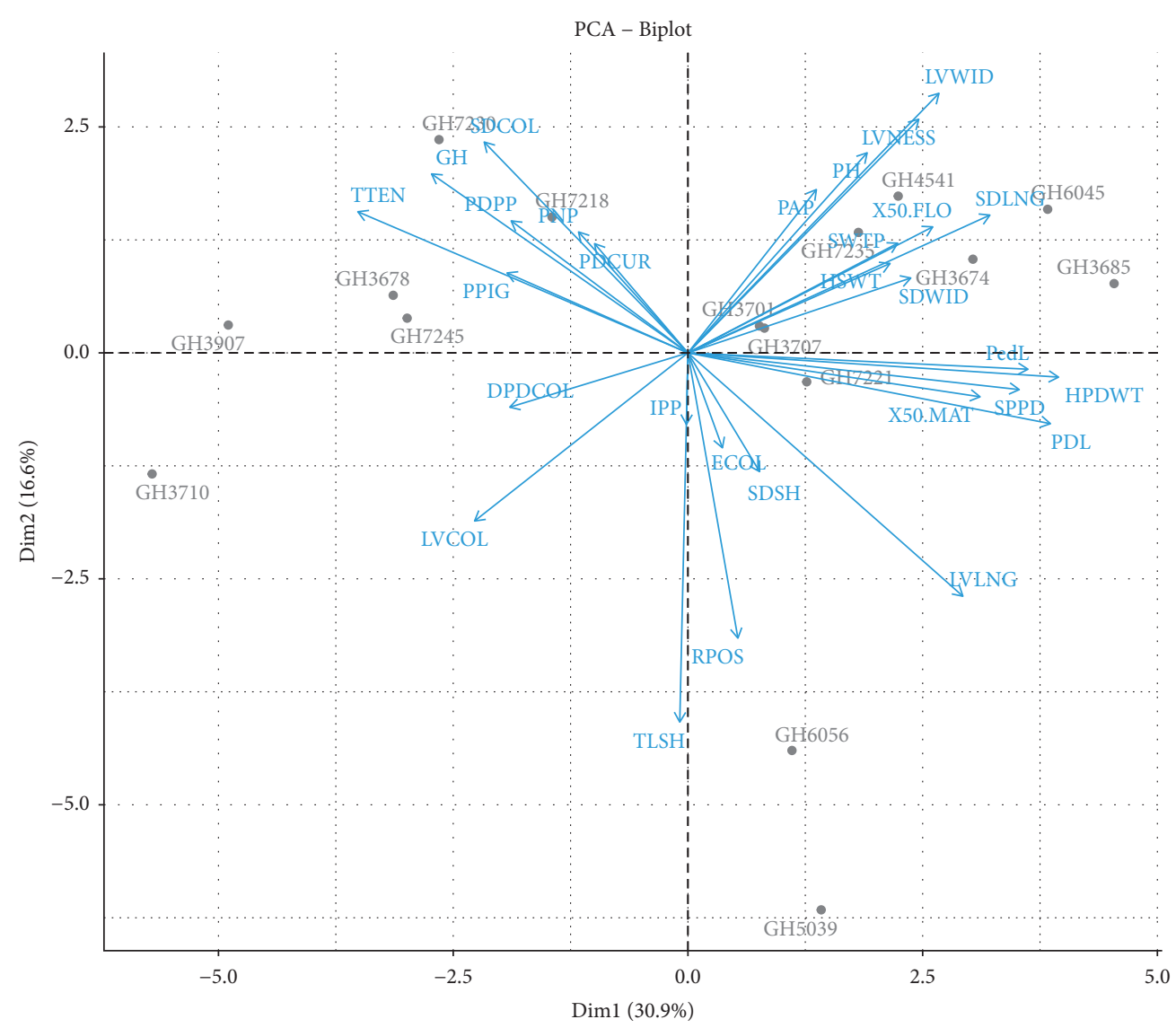

FIGURE 2: Biplot showing the association among agromorphological traits and genotypes. LVNESS = number of leaves, LVWID $=$ leaf width, $\mathrm{PAP}=$ pod attachment to peduncle, $\mathrm{PH}=$ plant height, $\mathrm{SWTP}=$ seed weight per plant, $\mathrm{HSWT}=$ hundred seed weight, $\mathrm{SDLNG}=$ seed length, SDWID = seed width, PedL = peduncle length, HPDWT $=$ hundred pod weight, $\mathrm{PDL}=$ pod length, $\mathrm{SPPD}=$ seeds per pod, $\mathrm{LVLNG}=$ leaf length, $\mathrm{SDSH}=$ seed shape, TLSH = terminal leaf shape, $\mathrm{PNP}=$ pod number per plant, $\mathrm{PDPP}=$ pods per peduncle, $\mathrm{GH}=$ growth habit, TTEN = twining tendency, PPIG = plant pigmentation, $\mathrm{PDCUR}=$ pod curvature, $\mathrm{IPP}$ - immature pod pigmentation, $\mathrm{DPDCOL}=\mathrm{dry}$ pod colour, $\mathrm{LVCOL}=$ leaf colour, $\mathrm{X} 50 . \mathrm{MAT}=$ days to $50 \%$ maturity, $\mathrm{X} 50 . \mathrm{FLO}=$ days to $50 \%$ flowering, $\mathrm{RPOS}=$ raceme position, $\mathrm{SDCOL}=$ seed colour, and $\mathrm{ECOL}=$ seed eye colour.

\section{Discussion}

4.1. Variability in the Accessions Based on Qualitative Traits. Variability was observed for most of the studied qualitative characters. Qualitative traits such as seed coat colour, pod and leaf colour, and growth habits are some important traits for selection as farmers and consumers preference are based on these attributes [14]. The growth of the accessions were indeterminate and vigorous. Vigorous growth are preferred due to the advantage of early establishment and dominance over weeds. Most of the accessions, which had prostrate or climbing growth had vigorous growth and subglobose terminal leaves, which may be a good candidate for cover crops. For pod attachment, the erect (13\%), 30-90 (25\%), and pendant (62\%) types were present. Though the erect type are mostly preferred for easy harvest, the pendant pods have been found to be longer and bore more seeds, which greatly influenced seed yield [35, 36]. Accessions GH3685 and GH3701 with long pods had pendant pod attachment to peduncle. The ideal one would, therefore, be pendant pods attached to long peduncles. The brown or straw dry pod colour was prevalent within the accessions. The colour of the pod could have been highly considered during the early domestication and selection process as genotypes with dark or black pods have been observed to shatter easily upon maturity [35].

Seed colour influences farmers' selection and consumer preferences as this usually have cultural and traditional dimensions [37]. Seed coat colour is often associated with processing quality (e.g., cooking time), and farmers deliberately select varieties that have shorter cooking time [38]. Grain yield and qualities, such as colour and ease of cooking, are known to be some basic objectives of most cowpea programmes [2]. The variability in seed colour observed here including those with multiple colours was very high.

4.2. Quantitative Traits of the Accessions. The agronomic variables varied among the studied accessions. The average days to flowering obtained here were comparable to the 41 days previously reported [14, 35]. However, within their collection, accessions with less than 30 days to flowering existed, which could be classified as extra early flowering. All the accessions had a high number of leaves probably owing 


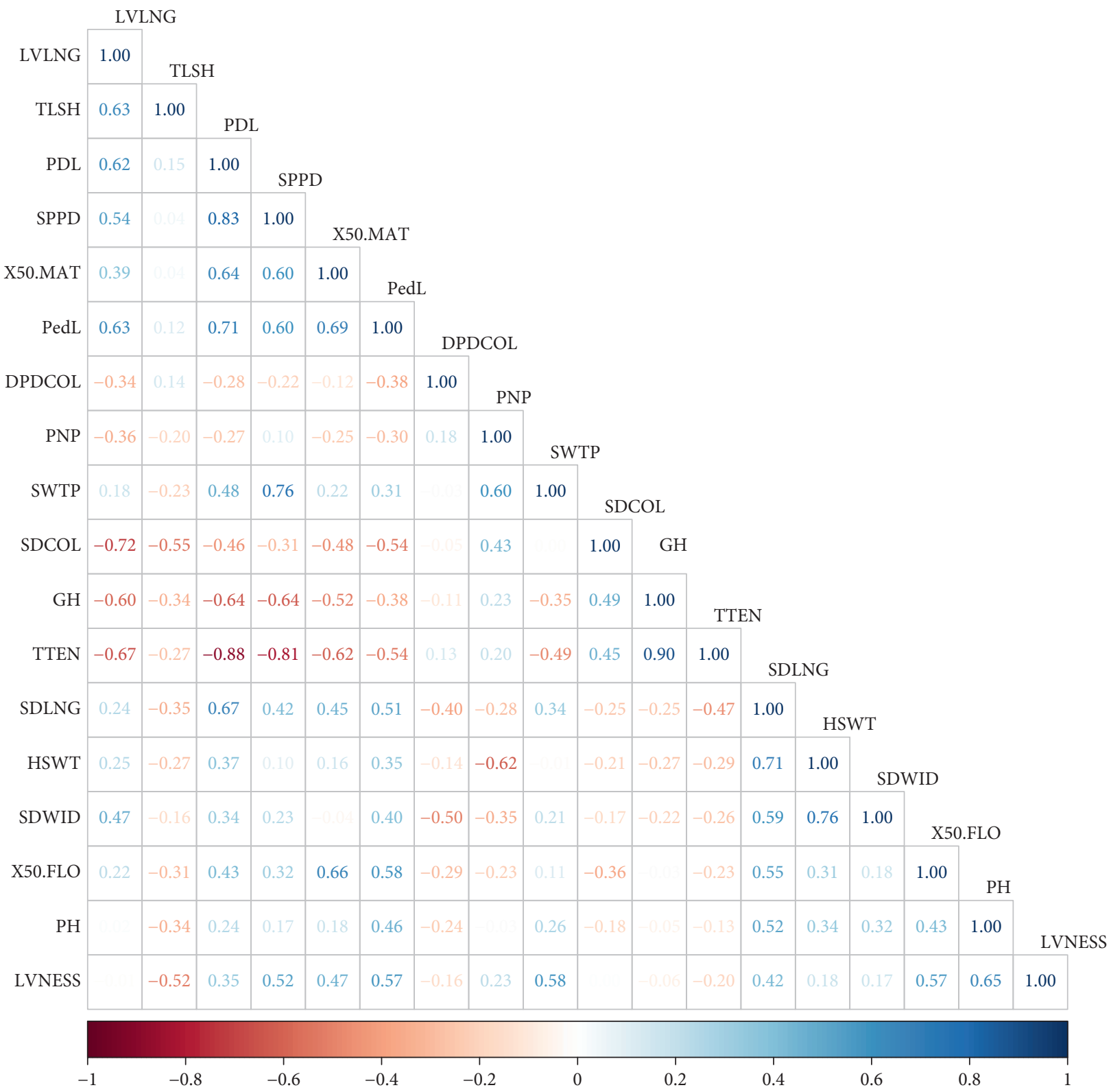

Figure 3: Correlations with $P$ value $>0.05$ were considered insignificant, and their correlation coefficient values were left blank.

to the creeping and climbing growth habit except GH5039 and GH6056, which had semierect growth habit. The variation in yield related traits such pod length, seeds per pod, and number of pods among the genotypes greatly influenced the seed weight per plant. GH3710 and GH4541 gave higher number of pods per plant; however, GH3710 had relatively fewer seeds due to its short pods as seed number is known to increase with longer pods [35]. Accession GH3674, GH3685, and GH4541 produced many pods per plant $(>30)$, which were relatively longer with more seeds. This, therefore, translated into the high seed weight per plant. Regarding the number of leaves, GH3685 and GH3674 produced a high number of leaves. The variations in the accessions for the studied traits provide room for improvement through selection and hybridization. GH3685, GH3674, and GH4541 though lacked the preferred seed/grain colour for commercialization, they could be an ideal genotype for backyard cultivation due to its indeterminate growth and high leaf production for long term vegetable supply, and its high number of pod production and long seeds and pods lead to high seed yield per plant [39]. GH3685, GH3674, and GH4541could therefore be good candidates in crop improvement for dual purpose cowpea, which is common in the subsistence farming system [6]. Future studies could also consider leaf harvesting frequency on the productivity of these potential genotypes.

4.3. Contribution of Traits to Observed Variability. At the phenotypic level, the accessions were distinguished by various characters since the major principal component (PC) axes were associated with varying traits. The first three 
TABLE 4: Estimates of variance components and genetic parameters for the quantitative traits.

\begin{tabular}{|c|c|c|c|c|c|c|c|}
\hline Traits & MSG & $\sigma^{2} \mathrm{e}$ & $\sigma^{2} \mathrm{~g}$ & $\sigma^{2} \mathrm{p}$ & $h^{2} b$ & GA & GAM (\%) \\
\hline PNP & $69.52^{*}$ & 31.26 & 12.75 & 44.01 & 0.29 & 4.14 & 13.29 \\
\hline PDL & $7.369^{* * *}$ & 0.17 & 2.40 & 2.57 & 0.94 & 3.03 & 17.78 \\
\hline HSWT & $4.75^{* * *}$ & 0.37 & 1.46 & 1.83 & 0.80 & 2.19 & 16.71 \\
\hline SPPD & $6.53^{* * *}$ & 0.66 & 1.96 & 2.62 & 0.75 & 2.62 & 17.49 \\
\hline $\mathrm{PH}$ & $10946.1^{* * *}$ & 3700.08 & 2415.37 & 6115.37 & 0.40 & 48.09 & 21.97 \\
\hline SWTP & $233.34^{* *}$ & 80.78 & 50.85 & 131.63 & 0.39 & 9.93 & 20.13 \\
\hline LVNESS & $593.41^{* * *}$ & 96.56 & 165.61 & 262.18 & 0.63 & 26.08 & 33.22 \\
\hline $50 \% . F L O$ & $2.48^{* *}$ & 0.28 & 0.73 & 1.01 & 0.72 & 1.47 & 3.74 \\
\hline 50\%.MAT & $7.91^{* * *}$ & 0.39 & 2.51 & 2.90 & 0.87 & 3.01 & 5.51 \\
\hline LVLNG & $11.91^{* * *}$ & 0.37 & 3.85 & 4.21 & 0.91 & 3.78 & 37.32 \\
\hline LVWID & $3.43^{* * *}$ & 0.37 & 1.02 & 1.39 & 0.73 & 1.77 & 26.60 \\
\hline HPDWT & $3529.9^{* * *}$ & 503.8 & 1008.70 & 1512.5 & 0.77 & 57.88 & 23.59 \\
\hline PDPP & $1.88^{*}$ & 0.53 & 0.41 & 0.94 & 0.43 & 0.68 & 25.47 \\
\hline PedL & $150.8^{* * *}$ & 7.209 & 47.86 & 55.07 & 0.87 & 13.09 & 32.93 \\
\hline SDWID & $0.0022^{* *}$ & 0.00064 & 0.0005 & 0.0012 & 0.45 & 0.04 & 7.05 \\
\hline
\end{tabular}

$\sigma^{2} \mathrm{~g}=$ genotypic variance, $\sigma^{2} \mathrm{e}=$ error variance, $\sigma^{2} \mathrm{p}=$ phenotypic variance, $\mathrm{h}^{2} \mathrm{~b}=$ broad-sense heritability, GA = genetic advance, GAM = genetic advance as percentage of the mean, MSG = genotype means square, and ${ }^{* *},{ }^{* *}$, and ${ }^{* * *}$ significant $P<0.05, P<0.01, P<0.001$, respectively.

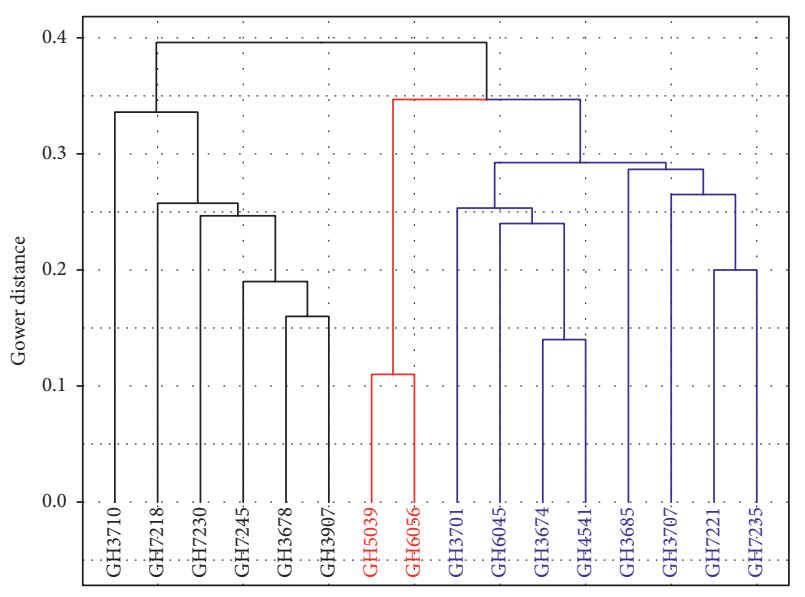

(a)

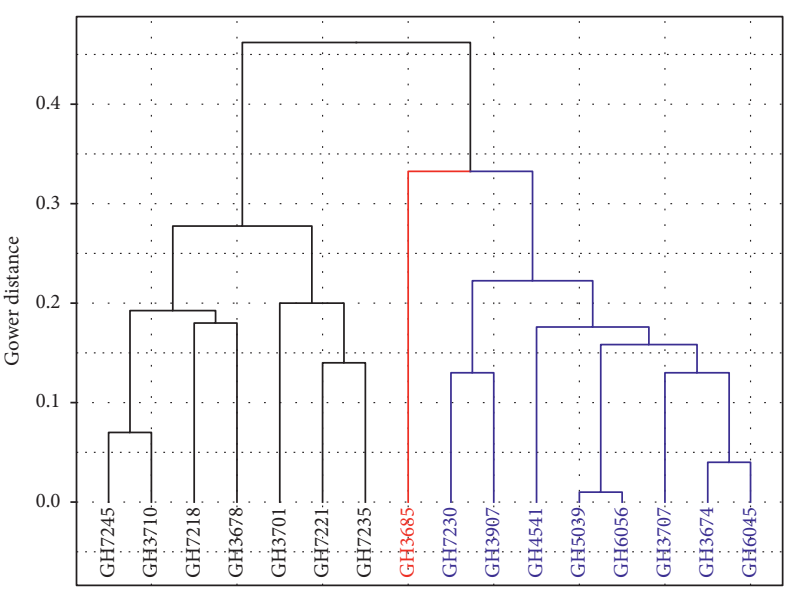

(b)

Figure 4: Dendrogram showing relatedness among the cowpea accessions. (a) Agromorphological; (b) silicoDArT.

principal component dimensions collectively accounted for about $60 \%$ of the total variation and were primarily associated with the pod (PC1: HPDWT, PDL, SPPD), leaf (PC2: TLSH, LVWID, LVLNG, LVNESS), and seed (PC3: SDWID, HSWT, SWTP) characters. Several authors have used cowpea leaf, pod, and seed characters to distinguish among cowpea lines and concluded that these are highly discriminatory traits in the identification of cowpea cultivars $[40,41]$. Seed colour, size, or yield may be used to group cultivars depending on the objective of the breeding programme and consumer's preference [2].

4.4. Relationship among Traits. Correlation studies enables the evaluation of the degree of association between two characters and the viability of indirect selection, which, in some cases, may lead to a progress faster than the selection of the desired character [42]. The PCA biplot (Figure 2) enables visual and simultaneous selection of genotypes for multiple traits. The biplot dimension vectors showed a high positive correlation among PDL, SPPD, and SWTP, indicating their positive impact on genotype performance. Nkoana et al. [43] and Walle et al. [44] identified these traits as important yield-influencing characters in cowpea. As indicated earlier, the phenotypic correlation corroborated the genotypic relationship among traits described in the PCA biplot (Figure 2), indicating low environment influence and, consequently, greater reliability of the use of these parameters in selection $[11,45]$.

The phenotypic correlation coefficients (Figure 3) estimated for 18 characters identified a strong significant association between PDL and SPPD and SWTP and PNP, as well as SPPD, which was in agreement with the report by [45], indicating that high SWTP may be obtained in an indirect manner with the selection for an increased number of pods per plant and SPPD [46]. The strong association between SWTP and LVNESS indicates the potential of leaf production on yield, hence the chance to select for high yield in terms of leaf and/or seed yield [39]. PNP correlated in a negative and significant way with HSWT, which allows 
inferences to be made regarding the possibility of joint selection for high PNP and HSWT to enhance grain yield $[14,47]$.

4.5. Heritability and Genetic Advance. The study demonstrated the presence of higher proportion of genotypic variance as a component of the total phenotypic variance for most of the selected growth and yield related traits. Similar observations were made by $[48,49]$ in their studies on variance and heritability of growth and yield parameters in cowpea. With reference to the grouping of heritability $\left(h^{2} b\right)$ as being high when $>0.5$, medium $0.3-0.5$, and low $<0.3$ by [50], all the traits except the number of pods per plant (PNP) could be considered to have moderate to high broad-sense heritability estimates. Shimelis and Shiringani [49] and Omoigui et al. [51] reported a heritability of 0.20 and 0.25 , respectively, for the number of pods per plant similar to the present estimate (0.29). The heritability estimate for HSWT (0.80), PDL (0.94), LVNESS (0.63), and X50\%FLO (0.72) was high, suggesting that these traits could be highly repeatable in the next generation through selection. This is in conformity with the 0.89 and 0.78 reported by [51] for HSWT and X50\%FLO, respectively. However, the $h^{2} b$ obtained for SWTP was moderate contrary to the $>0.5$ presented elsewhere [43, 49].

Genetic advance is directly related to gains achievable via selection. Traits with moderate to high heritability accompanied by high genetic advance as a percent of mean (GAM) indicates additive genetic effects leading to effective respond to selection, while high heritability with low GAM suggests a nonadditive genetic action $[52,53]$. Therefore, the heritability estimates and the high genetic advance indicate that selection would result in foreseeable genetic improvement in most of the traits [54], while 50\% FLO and 50\%MAT with low genetic advance estimates show the effects of equal contribution of additive and nonadditive gene action in the trait's expression [55].

4.6. Relationship among Cowpea Genotypes. The agromorphological data indicated wide variation among the accessions as seen in the three clusters. The early flowering and maturing accessions with numerous pods per plant constituted cluster one, while cluster three was made up of accessions, which had numerous leaves with long pods and a high number of seeds per pod. These distinguishable attributes of each cluster provide room for the selection and hybridization between clusters for crop improvement. Previous work by Egbadzor et al. [21] found accessions GH7218, GH7245, and GH7235 in the same group, while accessions GH3674 and GH4541 clustered together similar to our present study. Accession GH3685 singly formed cluster two based on silicoDArT data confirming the uniqueness of the genotype as revealed by the agromorphological data as good candidate for dual purpose cowpea.

The closest accessions phenotypically were GH5039 and GH6056 at a dissimilarity index of 0.11 , which were also identified by the silicoDArT data as being redundant at a dissimilarity index of 0.01. Genotypes GH5039 and GH6056 had different accession names in conservation, and the passport data also indicate different local names (Table 1); however, their collection occurred in the same location in Ghana (Abonse in Eastern region), which could influence the likelihood of being redundant. Sadiki et al. [56] and Agre et al. [57] indicated that the diversity within accessions from a common locality may be confounded due to the renaming of genotypes leading to synonymy and homonymy. Though phenotypically characterized, the low resolution of agromorphological markers could not detect the two redundant accessions, while the high-density silicoDArT markers demonstrated the ability to do so $[10,58]$. The discordance between phenotypic and silicoDArT data is partly due to the significant environmental effect on the variable expression, which could lead to the production of different phenotypes by even genetically identical individuals or clones [59]. The management of the duplicates could enhance germplasm curation activities. Therefore, morphological markers should be complemented with DNA-based markers for effective germplasm characterization and management $[11,13]$.

\section{Conclusion}

Agromorphological traits and genotyping using high-density silicoDArT markers revealed the presence of significant variation among some cowpea germplasm collections with an indeterminate growth pattern. The accessions varied for characters associated with the pods, leaves, and seeds. The study concluded on significant correlation between PNP, PDL, SPPD, LVNESS, and SWTP that could allow the selection to improve grain yield. Considerable degrees of genotypic variance, heritability, and genetic advance were also observed for important agronomic traits, indicating the potential for genetic improvement. The silicoDArT markers used in the study were able to deduce genetic variation among the tested cowpea collections. GH5039 and GH6056 were identified as redundant based on the silicoDArT markers. This will enhance efficient germplasm utilization and conservation. Accessions GH3685, GH3674, and GH4541 possessed good agronomic characters, which could be good candidates for dual purpose cowpea production. This will be useful in the selection of parents for improvement.

\section{Data Availability}

The research data used to support the findings of this study are included within the article.

\section{Conflicts of Interest}

The authors declare that they do not have any conflicts of interest.

\section{Acknowledgments}

We acknowledge the help received from Mr. Abednago Opoku and Theresa Offei, field technicians at the CSIRPlant Genetic Resources Research Institute, Bunso, Ghana. 
The genotyping through diversity array technology (DArT), Canberra in Australia was funded by AGRA through the IMCDA master's programme at KNUST.

\section{Supplementary Materials}

S1: qualitative data assessed. S2: Gower's dissimilarity index among the cowpea accessions based on agromorphological data. S3: determination of optimal clusters for grouping the accessions. S4: selected silicoDArT data used in the study. S5: Gower's dissimilarity index among the cowpea accessions based silicoDArT data. S6. Mantel correlation test between dissimilarity matrix based on silicoDArT and agromorph data. (Supplementary Materials)

\section{References}

[1] O. Boukar, F. Massawe, S. Muranaka et al., "Evaluation of cowpea germplasm lines for protein and mineral concentrations in grains," Plant Genetic Resources, vol. 9, no. 4, pp. 515-522, 2011.

[2] M. P. Timko and B. B. Singh, "Cowpea a multifunctional legume," in Genomics of Tropical Crops Plants, P. H. More and R. Ming, Eds., pp. 237-238, Springer, Berlin, Germany, 2008.

[3] S. A. Tarawali, B. B. Singh, M. Peters, and S. F. Blade, "Cowpea haulms as fodder," in Advances in Cowpea Research, pp. 313-325, IITA (International Institute of Tropical Agriculture), Ibadan, Nigeria, and JIRCAS (Japan International Research Centre for Agricultural Sciences), Tsukuba, Japan, 1997.

[4] B. B. Singh, H. A. Ajeigbe, S. A. Tarawali, S. Fernandez-Rivera, and M. Abubakar, "Improving the production and utilization of cowpea as food and fodder," Field Crops Research, vol. 84, no. 2, pp. 169-177, 2003.

[5] N. Sanginga, G. Thottappilly, and K. Dashiell, "Effectiveness of rhizobia nodulating recent promiscuous soyabean selections in the moist savanna of Nigeria," Soil Biology and Biochemistry, vol. 32, no. 1, pp. 127-133, 2000.

[6] S. S. Nielsen, T. A. Ohler, and C. A. Mitchell, "Cowpea leaves for human consumption: production, utilization, and nutrient composition," in Advances in Cowpea Research Ibadan:Copublication of International Institute of Tropical Agriculture (IITA) and Japan International Research Centre for Agriculture Sciences (JIRCAS), Tsukuba, Japan, 1997.

[7] R. J. Carsky, B. B. Singh, and B. Oyewole, "Contribution of early season cowpea to late season maize in the savanna zone of West Africa," Biological Agriculture \& Horticulture, vol. 18, no. 4, pp. 303-315, 2001.

[8] S. D. Tanksley and S. R. McCouch, "Seed banks and molecular maps: unlocking genetic potential from the wild," Science, vol. 277, no. 5329, pp. 1063-1066, 1997.

[9] B. A. Olukolu, S. Mayes, F. Stadler et al., "Genetic diversity in Bambara groundnut (Vigna subterranea (L.) Verdc.) as revealed by phenotypic descriptors and DArT marker analysis," Genetic Resources and Crop Evolution, vol. 59, no. 3, pp. 347-358, 2012.

[10] J. Duminil and M. Di Michele, "Plant species delimitation: a comparison of morphological and molecular markers," Plant Biosystems-An International Journal Dealing with all Aspects of Plant Biology, vol. 143, no. 3, pp. 528-542, 2009.

[11] B. G. Adu, A. Yeboah, and R. Akromah, "Whole genome SNPs and phenotypic characterization of cassava (Manihot esculenta crantz) germplasm in the semi-deciduous forest ecology of Ghana," Ecological Genetics and Genomics, vol. 17, Article ID 100068, 2020.

[12] S. H. Jansky, J. Dawson, and D. M. Spooner, "How do we address the disconnect between genetic and morphological diversity in germplasm collections?" American Journal of Botany, vol. 102, no. 8, pp. 1213-1215, 2015.

[13] P. A. Asare, I. K. A. Galyuon, J. K. Sarfo, and J. P. Tetteh, "Morphological and molecular based diversity studies of some cassava (Manihot esculenta crantz) germplasm in Ghana," African Journal of Biotechnology, vol. 10, no. 63, pp. 1390013908, 2011.

[14] N. Nkhoma, H. Shimelis, M. D. Laing, A. Shayanowako, and I. Mathew, "Assessing the genetic diversity of cowpea [Vigna unguiculata (L.) Walp.] germplasm collections using phenotypic traits and SNP markers," BMC Genetics, vol. 21, no. 1, 2020.

[15] H. T. T. Vu, A. T. James, R. J. Lawn, L. M. Bielig, and A. Kilian, "Use of DArT molecular markers for QTL analysis of droughtstress responses in soybean. I. Phenotypic evaluation of traits," Crop \& Pasture Science, vol. 66, no. 8, pp. 802-816, 2015.

[16] A. C. Hayward, R. Tollenaere, J. Dalton-Morgan, and J. Batley, "Molecular marker applications in plants," in Plant Genotyping: Methods and Protocols. Methods in Molecular Biology, vol. 124, pp. 13-27, , no. 5, Springer, Berlin, Germany, 2015.

[17] D. Jaccoud, K. Peng, D. Feinstein, and A. Kilian, "Diversity Arrays: a solid state technology for sequence information independent genotyping," Nucleic Acids Research, vol. 29, no. 4, p. E25, 2001.

[18] M. Akbari, P. Wenzl, V. Caig et al., "Diversity arrays technology (DArT) for high-throughput profiling of the hexaploid wheat genome," Theoretical and Applied Genetics, vol. 113, no. 8, pp. 1409-1420, 2006.

[19] P. K. Gupta, S. Rustgi, and R. R. Mir, "Array-based highthroughput DNA markers for crop improvement," Heredity, vol. 101, no. 1, pp. 5-18, 2008.

[20] N. H. Nguyen, H. K. A. Premachandra, A. Kilian, and W. Knibb, "Genomic prediction using DArT-Seq technology for yellowtail kingfish Seriola lalandi," BMC Genomics, vol. 19, no. 1, 2018.

[21] K. F. Egbadzor, K. Ofori, and M. Yeboah, "Diversity in 113 cowpea [Vigna unguiculata (L) Walp] accessions assessed with 458 SNP markers," SpringerPlus, vol. 541, no. 3, 2014.

[22] A. T. Asare, B. S. Gowda, I. K. A. Galyuon, L. L. Aboagye, J. F. Takrama, and M. P. Timko, "Assessment of the genetic diversity in cowpea (Vigna unguiculata L. Walp.) germplasm from Ghana using simple sequence repeat markers," Plant Genetic Resources, vol. 8, no. 2, pp. 142-150, 2010.

[23] S. V. Adu and R. D. Asamoah, "Soils of ayensu/densu basin, nta series (fao: gleyic arenosol)," Soil Research Institute Memoir, vol. 9, 1992.

[24] International Board for Plant Genetic Resources, Descriptors for Cowpea, IBPGR, Rome, Italy, 1983.

[25] A. Kilian, P. Wenzl, E. Huttner et al., "Diversity arrays technology: a generic genome profiling technology on open platforms," Data Production and Analysis in Population Genomics, vol. 888, pp. 67-89, 2012.

[26] Y. Gruenbaum, R. Stein, H. Cedar, and A. Razin, "Methylation of CpG sequences in eukaryotic DNA," FEBS Letters, vol. 124, no. 1 , pp. $67-71,1981$.

[27] H. W. Johnson, H. F. Robinson, and R. E. Comstock, "Estimates of genetic and environmental variability in soybeans 1," Agronomy Journal, vol. 47, no. 7, pp. 314-318, 1955.

[28] P. A. Miller, J. C. Williams, H. F. Robinson, and R. E. Comstock, "Estimates of genotypic and environmental 
variances and covariances in upland cotton and their implications in selection 1," Agronomy Journal, vol. 50, no. 3, pp. 126-131, 1958.

[29] R Core Team, A Language and Environment for Statistical Computing, R Foundation for Statistical Computing, Vienna, Austria, 2013, http://www.R-project.org/.

[30] S. Lê, J. Josse, and F. Husson, "FactoMineR: A package for multivariate analysis," Journal of Statistical Software, vol. 25, no. 1, pp. 1-18, 2008.

[31] R. Suzuki and H. Shimodaira, "Pvclust: hierarchical clustering with P-values via multiscale bootstrap resampling," 2015, http://stat.sys.i.kyoto-u.ac.jp/prog/pvclust/.

[32] J. C. Gower, "A general coefficient of similarity and some of its properties,” Biometrics, vol. 27, no. 4, pp. 857-871, 1971.

[33] F. E. Harrell and M. C. Dupont, Miscellaneous, https:// hbiostat.org/R/Hmisc/, 2020.

[34] H. Wickham, ggplot2: Elegant Graphics for Data Analysis, Springer-Verlag, New York, NY, USA, 2016, https://ggplot2. tidyverse.org.

[35] K. F. Egbadzor, E. Y. Danquah, K. Ofori, M. Yeboah, and S. K. Offei, "Diversity in 118 cowpea [vigna unguiculate (L.) walp] accessions assessed with 16 morphological traits," International Journal of Plant Breeding and Genetics, vol. 8, no. 1, pp. 13-24, 2013.

[36] F. A. Cobbinah, A. A. Addo-Quaye, and I. K. Asante, "Characterization, evaluation and selection of cowpea (Vigna unguiculata (L.) Walp) accessions with desirable traits from eight regions of Ghana," ARPN Journal Agricultural and Biological Science, vol. 6, pp. 25-32, 2011.

[37] Y. Mustapha, "Inheritance of seed colour in cowpea [Vigna unguiculata (L.) walp]," International Journal Pure Applied Science, vol. 2, pp. 1-9, 2008.

[38] O. Boukar, N. Belko, S. Chamarthi et al., "Cowpea (Vigna unguiculata): genetics, genomics and breeding," Plant Breeding, vol. 138, no. 4, pp. 415-424, 2019.

[39] M. Ngouajio, M. Saidi, M. F. Itulya, and J. N. Aguyoh, "Effects of cowpea leaf harvesting initiation time and frequency on tissue nitrogen content and productivity of a dual-purpose cowpea-maize intercrop," HortScience, vol. 45, no. 3, pp. 369-375, 2010.

[40] S. Kumar and M. Shrikant, "Evaluation of cowpea [vigna unguiculata (1.) walp.] cultivars using morphological indices," Asian Journal of Multidisciplinary Studies, vol. 4, no. 6, 2016.

[41] M. F. Alam, A. K. M. Siddiqui, K. M. Kabir, and A. Quasem, "Studies on the variability and genetic parameters in cowpea [Vigna unguiculata (L.) Walp.]," Bangladesh Journal of Plant Breeding and Genetics, vol. 1, no. 1-2, pp. 72-77, 1994.

[42] C. D. Cruz and A. J. Regazzi, Modelos Biométricos Aplicados Ao Melhoramento Genético, University of the Fraser Valley, Abbotsford, Canada, 2006.

[43] D. K. Nkoana, A. S. Gerrano, and E. T. Gwata, "Agronomic performance and genetic variability of cowpea (vigna unguiculata (L.) walp) accessions," Legume Resources, vol. 4, no. 6, pp. 757-762, 2019.

[44] T. Walle, F. Mekbib, B. Amsalu, and M. Gedil, "Genetic diversity of Ethiopian cowpea (vigna unguiculata L. Walp) genotypes using multivariate analysis," Ethiopia Journal of Agricultural Science, vol. 29, no. 3, pp. 89-104, 2019.

[45] A. d. Santos, G. Ceccon, L. M. C. Davide, A. M. Correa, and V. B. Alves, "Correlations and path analysis of yield components in cowpea," Crop Breeding and Applied Biotechnology, vol. 14, no. 2, pp. 82-87, 2014.

[46] C. H. A. Matos Filho, R. L. F. Gomes, M. M. Rocha, F. R. Freire Filho, and Â. C. d. A. Lopes, "Potencial produtivo de progênies de feijão-caupi com arquitetura ereta de planta," Ciência Rural, vol. 39, no. 2, pp. 348-354, 2009.

[47] M. A. Zaman, M. Tuhina-Khatun, M. Z. Ullah, M. Moniruzzamn, and K. H. Alam, "Genetic variability and path analysis of groundnut (Arachis hypogaea L.)," The Agriculturists, vol. 9, no. 1-2, pp. 29-36, 2011.

[48] M. F. Ishiyaku, B. B. Singh, and P. Q. Craufurd, "Inheritance of time to flowering in cowpea (Vigna unguiculata (L.) Walp.)," Euphytica, vol. 142, no. 3, pp. 291-300, 2005.

[49] H. Shimelis and R. Shiringani, "Variance components and heritabilities of yield and agronomic traits among cowpea genotypes," Euphytica, vol. 176, no. 3, pp. 383-389, 2010.

[50] S. Bhateria, S. P. Sood, and A. Pathania, "Genetic analysis of quantitative traits across environments in linseed (Linum usitatissimum L.)," Euphytica, vol. 150, no. 1-2, pp. 185-194, 2006.

[51] L. O. Omoigui, M. F. Ishiyaku, A. Y. Kamara, and S. G. Mahammed, "Genetic variability and heritability studies of some reproductive traits in cowpea (Vigna unguiculate (L.) Walp.)," African Journal of Biotechnology, vol. 5, pp. 11911195, 2006.

[52] V. G. Panse, "Genetics of quantitative characters in relation to plant breeding," Indian Journal of Genetics and Plant Breeding, vol. 17, pp. 318-328, 1957.

[53] A. K. Singh, A. K. Singh, P. Sharma, and P. K. Singh, "Studies on genetic characteristic of upland rice (oryza sativaL.)," International Journal of Agriculture Environment \& Biotechnology, vol. 6, no. 4, pp. 515-520, 2013.

[54] A. R. Pathak, M. R. Naik, and H. K. Joshi, "Heterosis, inbreeding depression and heritability for yield and yield components in cowpea," Electronic Journal of Plant Breeding, vol. 8, no. 1, pp. 72-77, 2017.

[55] S. N. Shelby, "Genetic studies in sweet potato genotypes under stress conditions," American Potato Journal, vol. 155, pp. 1453-1465, 2000.

[56] M. Sadiki, D. Jarvis, and D. K. Rijal, Variety Names an Entry Point to Crop Genetic Diversity and Distribution in Agroecosystems in Agricultural Ecosystems, Columbia University Press, New York, NY, USA, 2006.

[57] A. P. Agre, R. Bhattacharjee, I. Y. Rabbi et al., "Classification of elite cassava varieties (Manihot esculenta Crantz) cultivated in Benin Republic using farmers' knowledge, morphological traits and simple sequence repeat (SSR) markers," Genetic Resources and Crop Evolution, vol. 65, no. 2, pp. 513-525, 2017.

[58] M. Agarwal, N. Shrivastava, and H. Padh, "Advances in molecular marker techniques and their applications in plant sciences," Plant Cell Reports, vol. 27, no. 4, pp. 617-631, 2008.

[59] G. M. Volk, A. D. Henk, and C. M. Richards, "Genetic diversity among U.S. Garlic clones as detected using AFLP methods," Journal of America Society of Horticultural Science, vol. 129, pp. 559-569, 2004. 